\title{
A Structural Analysis of the Pakistani Fairy Tale the Moon King and Rose Princess
}

\author{
* Zahoor Hussain \\ ** Iram Rubab \\ *** Muhammad Ajmal (Corresponding Author)
}

\begin{abstract}
The purpose of this study was to have a structural analysis of fairy tales of Pakistan. Being a part of an old civilization, Pakistan has also the rich and centuries-old oral tradition of storytelling. The fairy tale The Moon King and Rose Princess of the same Pakistani traditional background was recorded and transcribed and analyzed using Propp's structural model. The analysis showed that all the 31 functions were present and these functions occurred in the plot in the same sequential arrangement as was given by Propp. The study had a conclusion that there are the same functions and their occurrences in the plot of the Pakistani fairy tales only with minor differences. The study received great admiration and recognized the Pakistani fairy tales.
\end{abstract}

Keywords: Structure, Fairy Tales, Propp, Oral Tradition, Narratives Introduction

Telling folktales has been a centuries-old tradition. Our forefathers adopted them as a medium of reflection of human life. Through the help of them, they came to know about the past events of human life and their history. Along with folktales, myths were also a considerable source of throwing light on past events. They explored their life events, experiences, and observations by constructing these narratives, with time, these observations and experiences acquired the form of folktales. According to Zipes (1996), these tales were passed on orally from one generation to the upcoming generation in many different forms i.e. fairytales, ballads, and fables. Further, folktales and fairy tales helped generations recognize their own cultures in-depth (Alembi, 1999). Wakituki (1999) also expands his point of view by making a statement that these tales are changed according to the time or the way they are described. This oral tradition received much importance by different researchers and linguists. In the oral tradition, two approaches like text and performance approaches are given much consideration. In linguistics along with comparative and structural aspects, the text approach has been given a place of importance. From these folktales not only historical elements are being studied but also their themes, structural patterns, and types are being over-viewed. Based on the difference between typology and structure, folklore has been set as a separate genre. Genre came out from a French word that stands for a class, type, and a kind. In linguistics, this classification helps in building some text and this also builds patterns of communication in every text. Researchers developed an interest to study the folklore to know the past events; this interest forced them to these pieces of writing again and again. Their main motive was to study these tales to know the socio-cultural, religious, and psychological perspectives of the past. Most important of them were those who found generic structures in these tales. They tried to gather information from both oral and written sources. This type of method can be seen in the psychological texts of the nineteenth century. So, finally, we can say that the progress of any knowledge is not possible without classification. The Saraiki fairy tales contain all the elements and functions found in established fairy tales of the world and can be analyzed by the Proppian Morphological model. No work has been done from the Pakistani perspective and this study would establish Saraiki folktales in Pakistan.

Literature Review

An intellectual and philosophical movement named 'structuralism' emerged in the $20^{\text {th }}$ century. In the field of research, it bought revolutionary progress. Different fields of studies like physics, anthropology, and psychology were considered as separated disciplines. Scholes (1974) pronounce that structuralism may be a response or reaction to a need-for some unified systems. He expands his

* BZ University Bahadur Campus Layyah Email: zahoor_linguist@bzu.edu.pk

** GC Women University Sialkot Email: iram.sial@yahoo.com

*** University of Lahore Email: muhammad.ajmal2@ell.uol.edu.pk 
point of view that structuralism is an "integrated, holistic way of looking at the world, including man" (p.3). Ferdinand de Saussure (1857) contributed a lot in the field of linguistics. He has been a professor at Geneva University. His lectures were collected by his disciple and under the title of Course de Linguistique General, they get them published in 1915. These lectures majorly focused on the history of words and their development with time. During the $19^{\text {th }}$ century, the main focus of researchers was diverted towards the historical perspective of language, they thought that language came out because of certain external and internal causes.

Another important figure, an anthropologist, Claude-Levi Strauss was a noticeable structuralist, who used to study myth, kinship, and culture with the help of structuralism. In 1971, he published 'Mythologies', which is based on the method of analyzing myths. According to Culler (1975) myth can be the performance of some symbolic system with some units and also the principles of joining them may be figured out. Strauss (2005) considered folktales as a 'transformation set' and was in view that folktales are based on different relations.

Barthes was a French literary critic and a structuralist. He wrote 'Mythologies' in 1957, which is based on his study of the culture of France. In 'Sarasin', he found five different codes of narrative, he also gave the concept of 'lexies' which is a minimal unit of meanings. These five codes are the following: the probiotic code, which is also known as the code of actions. This deals with all types of actions in some narratives. The hermeneutic code or code of puzzles, that deals with different questions of some narrative. Cultural code deals with certain culture of the narrative. The connotative codes deal with the qualities and attributes of different characters. Another important code is a symbolic code that deals with the themes of some kind of narrative. Greimas explains the difference between actors and actants. According to him in the narrative, actors have a link with actants, these actants are as following: a receiver, a helper, a sender, a subject, an object, and an opponent.

Herbert (2006) also worked in this regard on the idea of axis of power, transmission, and desire. Here we can see the relationship of desire as subject versus object; this link can be described as conjunction and also disjunction. This axis of power is explained through the junction of helper and opponent. The Axis of transmission is also known as the axis of knowledge, which is based on the junction of sender and receiver. This model is considered as a helpful method to create coherence in some narrative. While on the other hand Culler (1975) and Scholes (1974) criticized this model as it cannot meet the true needs of the narrative.

French-Bulgarian critic Todorov gave the concept of word narratology - the scientific study of narrative. Through this concept, he studied Boccacio's Decameron, for understanding this narrative's plot, he also studied or followed Propp's model. According to him, a plot is a movement from equilibrium to disequilibrium. He also gave the concept semantic view which deals with the content of the story, second is a syntactic view which deals with structural elements and the last one is a rhetoric view which deals with diction. As Propp was a Russian anthropologist, he studied the structure of Russian tales, he noticed the irreducible units of tales with structural perspective. Another important movement was Formalism, which also emerged in Russia. This movement has two main circles known as 'Moscow Linguistic Circle' and 'Petrograd Society'

Meletisky (2015) called Propp's model genuine, scientific, and advance of his age. Shaheen, Mumtaz, and Khalid (2019) did a study on gender ideology in fairy tales. The study indicated stereotypical portrayals of gender as males are presented as powerful and dominant and females vice versa. Kardar (2019) has done a detailed analysis of Wilde's fairy tales and came with the finding that Wilde exploited stylistic devices to foster interest and wonder among the readers. Khan (2020) did a motif analysis of Wilde's fairy tales and said that Wilde reflected his age through the use of motifs in his fairy tales.

\section{Propp's Structural Model}

Scholes (1974) praised Propp for conducting his research on Russian folktales because they are considered as proto-type of writing. Propp, s Morphology of Folktale was published in 1958 for the first time in the Russian language and later in English. Another important person named Sekonic (1994) cited Pelton in Folk Poetics in which he threw light on the two main points narrative first one is metamorphic and second is hermeneutic, in which he considered the logical aspects of folktales. In The Historical Roots of Magic Tales'. Ryan (2011) analyzed the historical motifs. Strauss (1996) criticized Propp for not considering this aspect. 
Propp (1928) analyzed one tale and divided the most repeated patterns into possible smallest points. These points are called functions and they are thirty-one in number. According to Propp, these spheres, "... define a character by his participation in a sphere of functions such spheres being limited in number, typical and subject to classification" (Barthes, 1975, p. 258). He called these functions stagnant which are either considered as signifiers or signified with different moves. These tales develop, events of the story can be changed through one or more than one move.

Propp's model has been validated by Gilt (1999) as he put forward five parts against his 31 functions such as interactions with the donor, circumstances, encounters with the king and villains, and return of the protagonist. Torries (2003) divided folktales into five parts such as talking tales, cumulative tales, realistic tales, drolls, romances, and tales of enchantment.

Table 1 Propp Thirty-One Functions

\begin{tabular}{|c|c|c|}
\hline Serial No. & Thirty-One Functions & Definition \\
\hline 1 & Absentation or $(\beta)$ & Absentation of the protagonist \\
\hline 2 & Interdiction represented as $(\gamma)$ & Cautioning and warning \\
\hline 3. & interdiction may be violated $(\delta)$ & Advance Cautioning is ignored \\
\hline 4. & Reconnaissance represented as $(\varepsilon)$ & Tracing places of various objects \\
\hline 5. & Delivery represented as $(\zeta)$ & Information about objects is given \\
\hline 6. & Trickery represented as $(\eta)$ & Alluring the characters \\
\hline 7. & Complicity represented as $(\theta)$ & Response to allurement \\
\hline 8. & Villainy represented as (A) & Misconduct or wrong acts \\
\hline 9. & Lack represented as $(\alpha)$ & Not enough space \\
\hline 10. & Mediation or Connective Incident as (B) & The Joining Incident \\
\hline 11. & Beginning Response or Counteraction (C) & Getting due leave \\
\hline 12. & Departure represented as $(\uparrow)$ & Dispatching the protagonist \\
\hline 13. & First action of a donor (D) & Help or the support to the protagonist \\
\hline 14. & Hero's Reaction represented as (E) & Reaction and response of the protagonist \\
\hline 15. & Provision of the magical object/ agent $(\mathrm{F})$ & The getting of object/ acquisition \\
\hline 16. & $\begin{array}{l}\text { Spatial Transference which occurs between } \\
\text { Kingdoms called Guidance }(\mathrm{G})\end{array}$ & $\begin{array}{l}\text { Moving towards the target between the } \\
\text { Kingdoms, }\end{array}$ \\
\hline 17. & Struggle represented as $(\mathrm{H})$ & Protagonist fights with antagonist \\
\hline 18. & Victory represented as (I) & Defeating the antagonist \\
\hline 19. & Lack or insufficiency liquidated given as $(\mathrm{K})$ & misfortune undone \\
\hline 20 . & The protagonist comes back $(\downarrow)$ & The hero returns \\
\hline 21. & The protagonist is followed or pursued (Pr.) & Villain tracks the hero. \\
\hline 22. & Rescue or saving one (Rs.) & The protagonist is saved. \\
\hline 23. & Unrecognized or unannounced Arrival (O) & An unrecognized supporter arrives \\
\hline 24. & Unfounded or false Claims (L) & The antagonist gives false vows \\
\hline 25. & Difficult or Tough Task (M) & The protagonist accomplishes it. \\
\hline 26. & Solution or Resolution as $(\mathrm{N})$ & The protagonist resolves situations. \\
\hline 27. & Recognition represented as (Q) & The protagonist is recognized. \\
\hline 28. & Exposure represented as (Ex.) & Pseudo hero is found. \\
\hline 29. & Transfiguration or Movement (T) & $\begin{array}{l}\text { The protagonist moves from one point to } \\
\text { the next. }\end{array}$ \\
\hline 30. & Punishment represented (U) & The Villain is punished. \\
\hline 31. & Wedding represented $(\mathrm{W})$ & The protagonist weds the princess. \\
\hline
\end{tabular}

Structural Analysis of the Fairy Tale the Moon King and Rose Princess

The researcher has applied the Proppian Model (1928-1968) which produced the following moves from above stated Saraiki folktale 'The Moon King and Rose Princess.' They are given below as
Move 1
Move 2
$\begin{array}{llllllllllllllll}\alpha & \text { a3 } & \uparrow & J & B & \eta 1 & \text { Q1 } & \text { A17 } & \text { E3 } & \text { F8 } & \eta 1 & 01 & \text { A17 } & \text { E3 } & \text { F8 }\end{array}$
$\uparrow \mathrm{G} 2 \mathrm{E3} \zeta 2 \mathrm{~F} 1 \mathrm{~W}$
Move 3
Move 4
Move 5

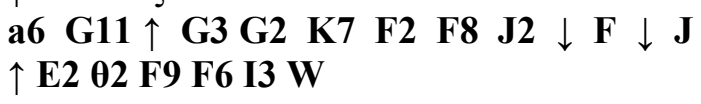
.$\downarrow \eta 3$ A10 L B4 G1 K F2 Q B4 F K2 E5 K5W

Though all the above-mentioned moves are interrelated yet there are new journeys, villains, deceits, and rewards given successively in the Saraiki folktale. Following is the structure of the first move: 


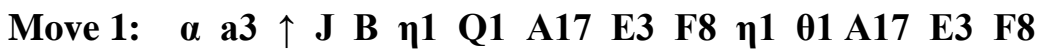

This tale started with the initial situation which followed by another function which is lack (a3), later the hero departs $(\uparrow)$ to search for it. Prince and his six brothers labeled or marked some point to gather after getting that object (J). Next function Meditation (B) follows the function villain persuasion $(\dot{\eta} 1)$. In the next function, the hero counters the previous one (Q1). In the next function human flesh-eating is (A17), hero saved the dead is function (E3) and agent ceased is function (F8). Later some actions have been repeated and fulfilled the function submission of villain $(\theta 1)$. Flesh-eating fulfils the next function (A7) and the hero's submission for a dead person is a function (F3) and (F8) is fulfilled with agent ceased.

The Saraiki folktale The Moon King and Rose Princess is based on different sorts of adventures. The moon king is introduced in the first move with a function initial situation which is according to Propp not a function so because of this reason this function has not been included in his thirty-one functions. This tale furthers with the lack of some object. This object is a plant that is considered to be a part of the royal garden (a3). The king orders all his sons from the first wife and from the second wife he called the king moon to collect that plant. The function of departure $(\uparrow)$ came when they all went to search for the object. They planned to gather at some specific point after getting that object, they marked that place (J), after it the next function counteraction started. Sons of king's wives took different directions (B). The moon king heard a call from a cannibal or a monster (ị1) who was pretending to be the father of a dead person. He helped the monster and this function fulfils the function of persuasion of villain $(\theta)$, as the monster started eating his body, with a sword the king moon grasped his ear (F8). This move also continues as the protagonist was sleeping and he heard a call from a woman $(\dot{\eta} 1)$ as he helped that woman she started eating the dead body (A17) but asking tried to capture her she escaped but king got a lock of her hair (E3). This tale follows all functions of Propp.

\section{Move 2:. $\uparrow$ G2 E3 ל2 F1 W}

The second move tells us about the departure of the hero to find the object which he was supposed to find. He reached at some other place (G2) to find it, he found some useful information about the place (E3). He gathers information about the queen and the king of that state who were villains (ל2). He got news that both the king and queen have lost their body parts, so the king moon gave them back their body parts (F1). After seeing his kindness king decided to wed his daughter with him (W). They also promised to support him in searching for that object. This move ends here.

The third move is constructed on the Proppian methodology which is the following.

Move 3: a6 G11 $\uparrow$ G3 G2 K7 F2 F8 J2 $\downarrow$ F $\downarrow$ J

This movie is about a journey that sometimes starts backward or forward. It also completes the function (a6) and the (G3), also the departure of the protagonist. In next step function (G3) and (G2) is fulfilled by hero's ride on the back of the horse. Finally, the object is searched (K7) and F2 and f8 are also completed here. At the next point, the function $\mathrm{J} 2$ is completed when both the previous and the hero exchanges ring with the handkerchief. He came back to the place of his in-laws $(\downarrow)$ successfully. He got a lock of hair (F) and returned ( $\downarrow$ ) back to the palace. Then he started the journey back to the place which they marked to gather after getting the object $(\mathrm{J})$.

Here the climax of the story begins. He started his journey with the support of the donor (G17) and the function $(\uparrow)$ is also fulfilled when the hero traveled alone. He reached the palace where a magical horse was waiting for him that takes him to the princess (G2). There he captured the amazing object (K7). There a cat appeared (F2) and then the protagonist seized it that fulfils the function (F8). As he reached his in-laws' palace, they instruct him to heat the lock whenever he finds himself in trouble. He reached the marked place $(\mathrm{J})$, here the third movie ended.

Following is the structure of the fourth move produced after the application of the Proppian Model (1928);

\section{Move 4: $\uparrow$ E2 02 F9 F6 I3 W}

Following is the last move of folktale produced after the application of the Proppian Method:

This move started with the departure of the hero $(\uparrow)$ that later fulfils the next function (E2), Q2 function completed as the hero surrenders and becomes the prey to the cruelty of the villain. Next function F9 deception is fulfilled and as the agent came out of the bag F6, the antagonist is defeated. In the end, as the hero marries, he gets a reward by accessing to throne. 
Another adventure started $(\uparrow)$ with the departure of the hero. A witch tricked people by playing a card game. She used to turn the losers into stone form. The hero was in search of her (E2), he insisted her to play with him (Q2) at that night of game, cat came out of the bag and it made her mouse scared which helps her in winning the game. So this time, she lost the game as the mouse was unable to help her I3. After that, she was forced to marry the hero and let him access to her throne (W). At the end of this move of the tale, he also got freed his brothers from that witch.

\section{Move 5: $\downarrow \eta 3$ A10 L B4 G1 K F2 Q B4 F K2 E5 K5W}

This fifth move is the last movie of the tale, which is according to the methodology of Propp. This move started with the protagonist's return $(\downarrow)$. It follows the next move which is trickery $(\dot{\eta} 3)$. In this function of villainy, the hero was cast into a well by the antagonist (A10), function ' $L$ ' is followed with the baseless claims of both the hero and the villain (B4). Function $G$ is completed with his transference in the air to search the object F2. That task is completed (Q). Function B4 started with the misfortune of the prince as he calls someone for help (B) and that object is known (FK2), then his misfortune met an end K5. In the end hero is rewarded (W) and the villain was punished.

As the hero frees his brothers, on the way back to their home, they insisted king moon to bring water as they were pretending to be thirsty $(\dot{\eta} 3)$. As he went to bring water, his brothers tried to throw him into the well (A10). So that they may get that object and at home, they may claim to be successful in getting that object (L). As the princess wakes up, she sees that her object is lost, she visits many palaces to find her object back, finally she reached at king moon's palace, they brought the object to her, she insists to have that thief, the king was requesting her to have mercy (E5), and there she recognizes her ring. Father of king moon calls king moon to help them, asking moon heated that lock given by his in-laws, some supernatural powers help them to get safe themselves from that princess (K5). After seeing his bravery the princess marries him (W). So here the last movie ended.

\section{Conclusion}

In this analysis, the researchers tried their best to associate all these thirty-one functions in this folktale introduced by Propp. All the functions of this tale occurred according to Propp's methodology. So there was only one exception of deviation from the Proppian model in the plots. In Saraiki tales, the hero can perform both roles of an antagonist and the protagonist. There are few deviations in Saraiki folktales in following Propp's scheme but these are not as much in number which can disturb the structure of the tale. The analysis of the Saraiki fairy tale proved that Saraiki fairy tales had all the same types of functions and structures as found in the international fairy tales in the world. The Study established the Saraiki fairy tales and earned respect for them as they were studies for the first time through Propp's morphological model.

\section{References}

Alembi, E. (1999). Narrative performance in a changing world: the case of the "Storyteller" in Kenya. In M. read (Ed), Traditional Storytelling Today: An international sourcebook (PP.68-70). Chicago \& London: Fitzroy Dearborn Publishers. Amsterdam - New York,

Haase, D. (2008). The Greenwood Encyclopedia of Folktales and Fairy Tales, Volumes 1-3:

Hebert, L. (2006). 'The Actantial Model'. In Lous Hebert (dir.) Signo [online] Rimouski (Qubec) http:// www.signosemio.com (29.8.2012)

Jason, H. (2000). Motif Type and genre.A Manual for Compilation of Indices \& a Bibliography of Indices and Indexing. Helsinki: SuomalainenTiedeakatemia.

Kadir, S. (2019). A Stylistic Analysis of Oscar Wilde's The Nightingale and The Rose. Opcion, 35(19), 2899-2921.

Khan, M, Hussain, Z., Ahsan, M. (2020). Motif Analysis of Oscar Wilde's Fairy Tales. Research Journal of Social Sciences \& Economics Review. 1(3), 265-273.

Killeen, J. (2007). Fairy Tales of Oscar Wilde Surrey: Ashgate Publishing.

Levi-Strauss, c. (1984) 'Structure and Form: Reflections on a Work by Vladimir Propp'. (Trans, Monique Layton) in Vladimir Propp (1984) 167-199)

Meletinsky, E. (2015). Structural-Typological Study of Folktales. New York: University Library Technical Service.

Pateman, T. (2005).Structuralism and Narrative.www.selectedworks.co.uk (12-05-2012).

Propp, V. (1968).Morphology of the Folktale. (Trans. By Laurence Scott) Bloomington: Indiana University [Originally Published in 1928] 
Quintus, A. J. (1991). 'Christ, Christianity, and Oscar Wilde'. Texas Studies in Literature and Language 33/4: 514-527

Rahman, R. (2011). Semantico- Syntactic Features of Oscar Wilde's Fairy Tales. Ph.D. Thesis (Unpublished), University of Peshawar.

Ryan, M. (2011). Cyberage Narratology, Computers, Metaphor, and Narrative. Narratologies: New Perspectives on Narrative Analysis. Columbus: Ohio State UP.

Shaheen, U., Mumtaz, N., Khalid, K. (2019). Exploring Gender Ideology in Fairy Tales- A Critical Discourse Analysis. European Journal of Research in Social Sciences. 7(2), 2056-5429.

Schmidgall, g. (1994).The Stranger Wilde: Interpreting Oscar. New York: Dutton

Scholes, R. (1974). Structuralism in Literature: An Introduction. New Haven: Yale University Press.

Sekoni, R. (1994). Folk Poetics: A Sociosemiotic Study of Yoruba Trickster Tales. Greenwood Press, Westport, Connecticut, London.

Snider, C. (2009)." On the Loom of Sorrow".Eros and Logos in Oscar Wilde Fairy Tales.www.csulb.edu/ csnider/wilde.fairy.tales/html (25.7.2013)

Summers, C.J. (1990). GAY FICTIONS: Wilde to Stonewall. Studies in a Male Homosexual Literary Tradition. New York: Continuum.

Swales, J. (1990).Genre Analysis.Cambridge: Cambridge University Press

Thompson, S. (1946). The folktale. New York: Dryden.

Tories (2003), Traditional Tales: North American Fungi 3(7): 23-72)

Wailuku, v. (1999). Storytelling: a thread of life within the Kamba community. In. M. Read, Traditional storytelling today: An international sourcebook (pp. 65-75). Chicago \& London: Fitzroy Dearborn Publishers.

Willoughby, G. (1993). Art and Christhood: The Aesthetics of Oscar Wilde. New York: Fairleigh Dickinson.

Zipes, J. (1983). Fairy tales and the Art of Subversion: The Classical Genre for Children and the Process of Civilization. New York: Heinemann

Zipes, J. (1996). "Towards a theory of the Fairy-Tales Film: The Case of Pinocchio: .The Lion and the Unicorn 20/1:1-24

Zipes, J. (Ed.). (2001) The Great Fairy tales Tradition: From STRAPAROLA and BASILE to the BROTHERS GRIMM. A Norton Critical Edition. New York: w.w.\& company. 